\title{
Study of the Stability of a Soil-Rock Road Cutting Slope in a Permafrost Region of Hulunbuir
}

\author{
Yuxia Zhao $\mathbb{D}^{1},{ }^{1}$ Jun Feng $\mathbb{D},{ }^{2}$ Kangqi Liu $\mathbb{D},{ }^{1}$ Hongwei Xu $\mathbb{D},{ }^{1}$ Liqun Wang $\mathbb{D},{ }^{3}$ \\ and Hongyan Liu $\mathbb{D}^{1}$ \\ ${ }^{1}$ School of Engineering and Technology, China University of Geosciences, Beijing 100083, China \\ ${ }^{2}$ School of Airport Engineering and Transportation Management, Civil Aviation Flight University of China, \\ Guanghan 618307, China \\ ${ }^{3}$ Beijing Municipal Road \& Bridge Group Co., Ltd., Beijing 100009, China
}

Correspondence should be addressed to Hongyan Liu; zyxcugb@sina.com

Received 6 February 2020; Revised 24 October 2020; Accepted 26 October 2020; Published 23 November 2020

Academic Editor: Pingye Guo

Copyright (C) 2020 Yuxia Zhao et al. This is an open access article distributed under the Creative Commons Attribution License, which permits unrestricted use, distribution, and reproduction in any medium, provided the original work is properly cited.

Due to the threat of global warming and the accelerated melting of glaciers and permafrost, the stability of slopes in permafrost regions has received an increasing amount of attention from scholars. However, research on the stability of soil-rock road cutting slopes in high-latitude and low-altitude permafrost regions of the Greater Khingan Mountains in the Inner Mongolia Autonomous Region has not been reported. For this reason, a study of the stability of a slope with a high ice content in section $\mathrm{K} 105+600$ to K105 + 700 of National Highway 332 is conducted. The slope is $20 \mathrm{~m}$ high and the slope angle is $45^{\circ}$, and the risk of landslides on this slope under the action of freeze-thaw erosion is very high. Because of this, field in situ monitoring, indoor freezethaw tests, thermal parameter tests, and ABAQUS numerical simulation models are used to study the stability of the slope. After collecting the continuous temperature, moisture, settlement, and slope deformation data, it was found that the slope was undergoing dynamic changes. The creep of shallow slopes increased with the number of freeze-thaw cycles. After approximately 150 freeze-thaw cycles, the slope safety factor was less than 1, which means that the slope had reached the limit equilibrium state. Therefore, freeze-thaw erosion greatly reduced the stability of the slope. Hence, the stability of the slope must be protected during its entire life cycle. This study provides a reference for the design and construction of road cutting slopes in the high-latitude and low-altitude permafrost regions of the Greater Khingan Mountains.

\section{Introduction}

Frozen soil refers to various rocks and soils that are below $0^{\circ} \mathrm{C}$ and contain ice. Frozen soil can generally be divided into shortterm frozen soil (a few hours/days or even half a month), seasonal frozen soil (half a month to several months), and permafrost (soil layers that have been frozen for two years or more) [1]. Permafrost covers approximately $20 \%$ of the earth's land area [2]. China's permafrost area accounts for $22.3 \%$ of the country's land area, ranking the third in the world, and the area of high-altitude permafrost is the largest in the world. Seasonal frozen soil spreads over most of the country $[3,4]$. Permafrost is extremely sensitive to temperature changes [5].

When the water in the soil pores and its parent material or in rock fractures is frozen, its volume expands and the fracture increases, resulting in the fragmentation of the entire soil or rock. After ablation, its anticorrosion stability is greatly reduced. Under the action of gravity, the rock and soil move downward along the slope, which is called freeze-thaw erosion [6]. Freeze-thaw erosion is the primary factor for the creep and slippage of slopes in permafrost regions [7]. Due to the freezethaw cycles, many landslides have occurred in permafrost regions. Chen et al. concluded that the instability of a slope can seriously damage road traffic infrastructure and property and even cause casualties [8-11]. For this reason, the majority of scientific researchers have conducted many studies on the stability of slopes in cold regions. For example, Tao et al. conducted laboratory testing, numerical analyses, and field monitoring research on a soil-rock slope. They found that slope stability was significantly impacted by the freeze-thaw action 
because the slope safety factor was reduced from 2.61 to 2.24 after only one freeze-thaw cycle $[12,13]$. Chou et al. concluded from experiments that the slope safety factor negatively correlated with the gradient under the action of freeze-thaw cycles. As the number of freeze-thaw cycles increased, the cohesion and slope safety factor in loess regions both showed an exponential decay trend [14-18]. Zhang et al. concluded that the silt embankment slope stability decreased significantly due to freeze-thaw erosion, up to 51\% [19-21]. Wang et al. studied the highway slope of Jinghe to Yining counties of the G577 line with the aid of coupled stress fields, seepage fields, chemical fields, and the COMSOL simulation model. They found that the more the freeze-thaw cycles, the greater the possibility of landslides [22-24]. Moreover, Wang et al. found that as the porosity of the slope increased, irreversible freeze-thaw damage occurred to the slope, and the closer the slope foot, the greater the damage [25-29].

However, the research on the stability of road cutting slopes under freeze-thaw erosion in high-latitude and low-altitude permafrost regions of the Greater Khingan Mountains in the Inner Mongolia Autonomous Region has not been reported. Therefore, a study on the stability of a representative slope in this area was conducted by means of in situ monitoring, indoor freeze-thaw tests, thermal parameter tests, and ABAQUS numerical simulation models, which is of great guiding significance for stability evaluations and the treatment of other similar slopes. In addition, this study provides effective prevention and cure of slope freeze-thaw hazards and a rational design for slopes for environmental protection and to protect the safety of life and property.

\section{Materials and Methods}

2.1. Overview of the Study Site. Figure 1 shows the geographic location of the study site. The soil-rock road cutting slope $\left(50^{\circ} 35^{\prime} 30^{\prime \prime} \mathrm{N}, 123^{\circ} 43^{\prime} 34.31^{\prime \prime} \mathrm{E}, 775 \mathrm{H}\right)$ is located in the permafrost regions of the Greater Khingan Mountains in Hulunbuir, which is the coldest place in eastern China. This area has an east longitude of $121^{\circ} 55^{\prime}-125^{\circ} 10^{\prime}$, a north latitude of $50^{\circ} 10^{\prime}-53^{\circ} 33^{\prime}$, an altitude of $540-810 \mathrm{~m}$, a severe winter (average temperature $-24^{\circ} \mathrm{C}$ ), and an annual evaporation of less than $1,200 \mathrm{~mm}$. The region belongs to a cold-temperate semiarid continental monsoon climate. The winter is up to seven months, with severe cold, dry weather, and cold waves. The temperature rises sharply in spring, with many strong winds, and the summer is short and hot. The temperature drops sharply in autumn, with an average temperature below $4^{\circ} \mathrm{C}$. Second, the frost often comes early, and the frost-free period is short, the heat is insufficient, and the temperature difference between day and night is large. Third, sunshine is abundant in this region, and the annual sunshine duration is greater than 2700 hours. In addition, the annual precipitation in this area is $250-350 \mathrm{~mm}$, which has the characteristics of large difference and uneven distribution, and the precipitation is primarily concentrated during July and August, accounting for $65 \%-70 \%$ of the annual precipitation. Moreover, the average annual temperature in this area is between $-2.7^{\circ} \mathrm{C}$ and $-0.8^{\circ} \mathrm{C}$. July has the highest temperature, with an average of $17.9^{\circ} \mathrm{C}-19.8^{\circ} \mathrm{C}$. The highest temperature is $37.5^{\circ} \mathrm{C}$. The average temperature of the coldest month (January) is -18 to $-30^{\circ} \mathrm{C}$. The monthly temperature change trend of this permafrost region for the past three years is shown in Figure 2. As can be seen from Figure 2, the temperature in this area changes drastically, and the temperature difference is very large, so the freeze-thaw effect is strong [30-39]. Therefore, the stability of a slope under this freeze-thaw cycle is worth investigating.

\subsection{Experimental Design}

2.2.1. Sample Preparation. The volcanic breccia rock specimens were taken from the soil-rock road cutting slope at the $\mathrm{K} 105+600-\mathrm{K} 105+700$ section of the Ali River to the Kubuchun Forest Farm on the National Highway 332 of Hulunbuir of the Inner Mongolia Autonomous Region, China. The area belongs to the permafrost region of the Greater Khingan Mountains. The road cutting slope is located in a low mountain and hilly landform area, where the surface vegetation is relatively developed, the slope is facing the sun, the slope of the mountain is large, and the uneven settlement of the existing road below the slope foot is serious.

The slope is full of volcanic breccia. After drilling and sampling on-site, the specimens were transported back to the laboratory for cutting and grinding, and a specimen's size under freeze-thaw was $\Phi 50 \mathrm{~mm} \times 100 \mathrm{~mm}$. The size and accuracy of the specimen met the relevant requirements in the Standard for Test Methods of Engineering Rock Masses [40]; that is, the ratio of the height of the specimen to the diameter was between 2.0 and 2.5. The diameter of each specimen was between $48 \mathrm{~mm}$ and $54 \mathrm{~mm}$, and this diameter was greater than 10 times the diameter of the largest particle in the rock. The diameter error of the specimen did not exceed $0.3 \mathrm{~mm}$ over the entire height, and the two end surfaces of the test piece were flat. In addition, the nonparallelism of the two end surfaces did not exceed $0.05 \mathrm{~mm}$ at the maximum. The end face of the specimen was perpendicular to the axis of the specimen, and the maximum deviation did not exceed $0.25^{\circ}$.

Based on the experience and practices of many predecessors in this research field [41-46] and the corresponding experimental procedure [47], the samples were evacuated under a vacuum and then saturated with water before the freeze-thaw experiment. After screening, a total of fifteen samples were selected and divided into five groups according to the formation depth, with three samples in each group, as shown in Figures 3(a) and 3(b). The samples before the freeze-thaw experiment are shown in Figure 3(a), the samples in the freezing stage during the 150th freeze-thaw cycle are shown in Figure 3(b), and the samples after 150 freeze-thaw cycles are shown in Figures 3(c) and 3(d).

In the thermal parameter tests, the samples were powdered when the thermal conductivity was measured. The sample size was $\Phi 30 \times 80 \mathrm{~mm}$ when the specific heat capacity was measured, and the sample size was $10 \mathrm{~mm} \times 10 \mathrm{~mm} \times 50 \mathrm{~mm}$ when the thermal expansion coefficient was measured.

2.2.2. Field Monitoring Site Layout. In order to observe the shallow slippage of the slope during the freeze-thaw cycle in a comprehensive manner, an observation point was 


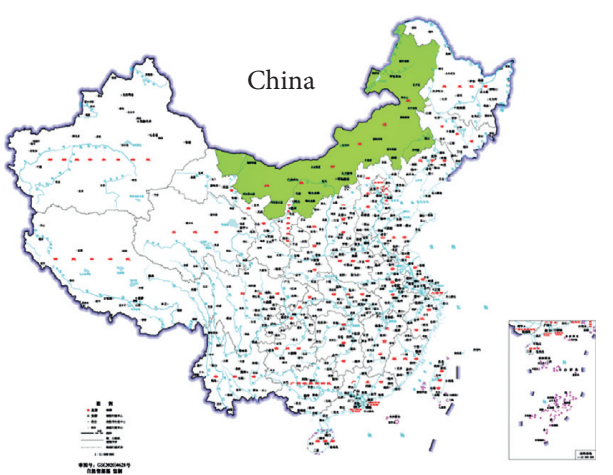

(a)

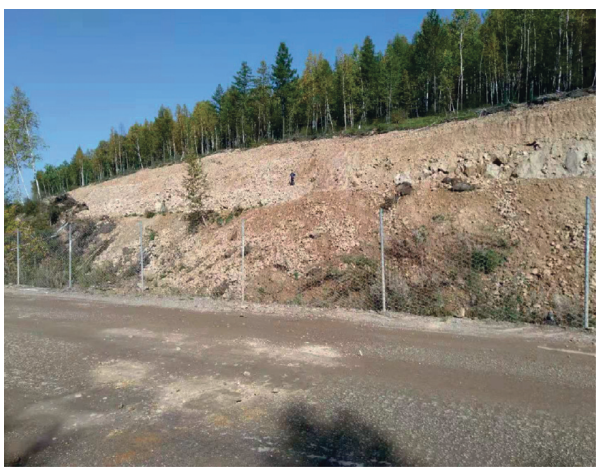

(c)

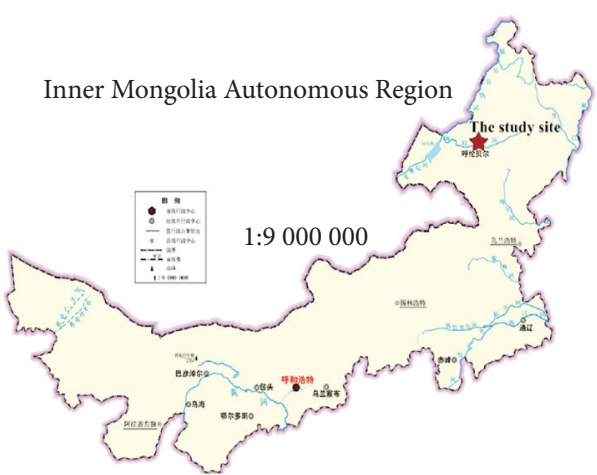

(b)

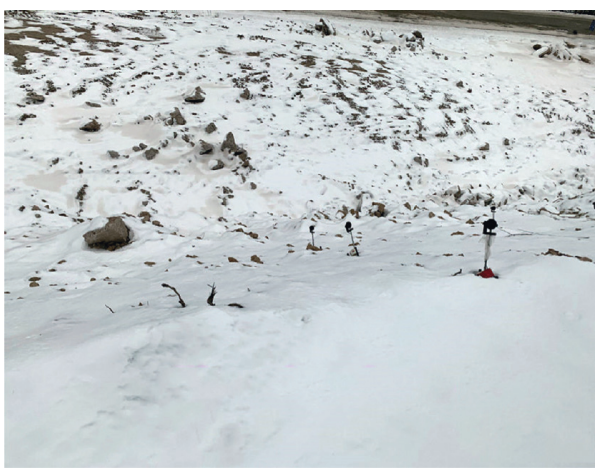

(d)

Figure 1: Geographic location of the study site. (a) The location of the study site in China; (b) the location of the study site in the permafrost region of the Greater Khingan Mountains in the Hulunbuir, Inner Mongolia Autonomous Region; (c) the landscape of the field monitoring site; and (d) the cutting slope covered by a large amount of snow in winter.

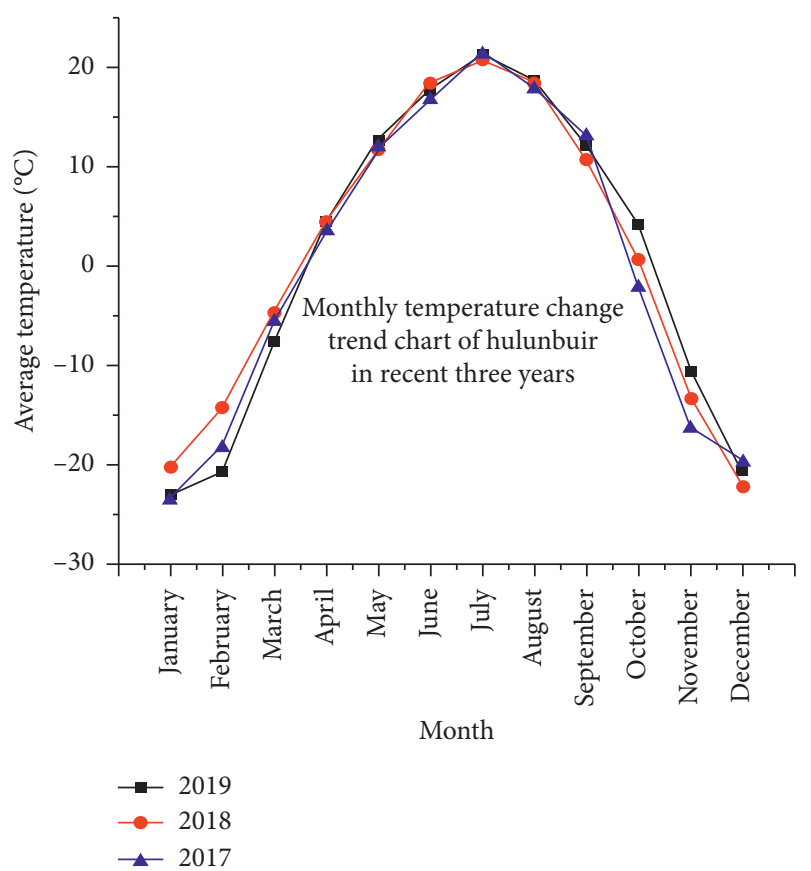

FIgURE 2: The temperature trend chart of the study site for the most recent three years.

established within every $3 \mathrm{~m}$ radius on the slope surface to continuously obtain the slope deformation and settlement throughout the year. The arrangement of the observation points on the slope is shown in Figure 4(a). The measurement process of the temperature data in the slope is shown in Figure 4(b). The height of the slope was $20 \mathrm{~m}$. In order to obtain the temperature of each layer in the slope, drilling was performed from the top of the slope to the immobile rock layer at the bottom of the slope. The drilling depth was $25 \mathrm{~m}$, and a temperature field sensor was arranged every $1 \mathrm{~m}$ along the drilling depth. In order to fix the temperature sensors to the specified depth, the temperature sensors were bound to the anticorrosion steel pipe and lowered to the specified depth, as shown in Figure 4(d). When observing the deformation and settlement of the slope, the drilling point was selected as the control point, as shown in Figure 4(e). Moreover, in order to obtain the moisture content in the slope, a moisture sensor was vertically arranged every $1 \mathrm{~m}$ along the depth of the slope. The probe directions of the moisture sensors were perpendicular to the pit wall. The arrangement of the moisture sensors is shown in Figure 4(c).

\section{Results}

3.1. Freeze-Thaw Cycle Damage to the Samples in the Slope. Freeze-thaw cycle experiments were conducted on the samples representing five different strata in the slope. The samples underwent a total of 150 freeze-thaw cycles. Each freeze-thaw cycle lasted 24 hours, of which the freezing lasted 12 hours and the melting lasted 12 hours. The freezing temperature was $-20^{\circ} \mathrm{C}$, and the melting temperature was 


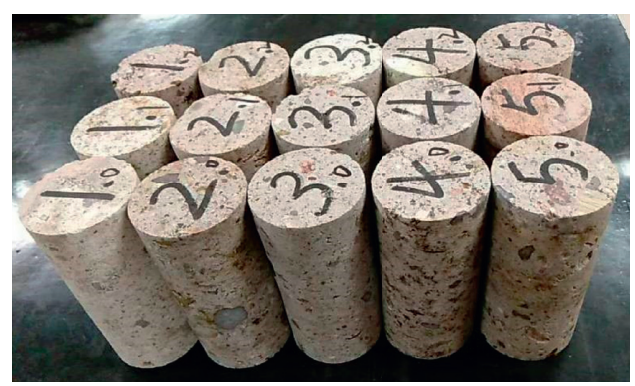

(a)

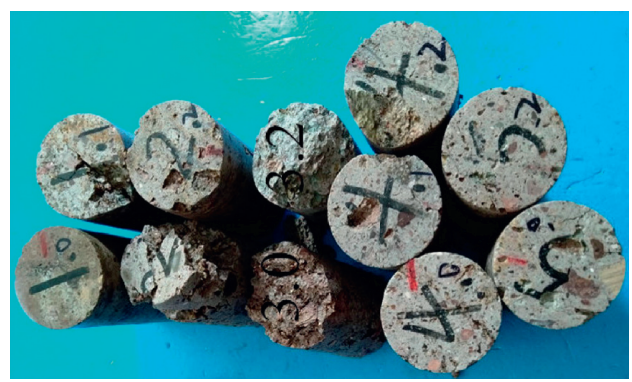

(c)

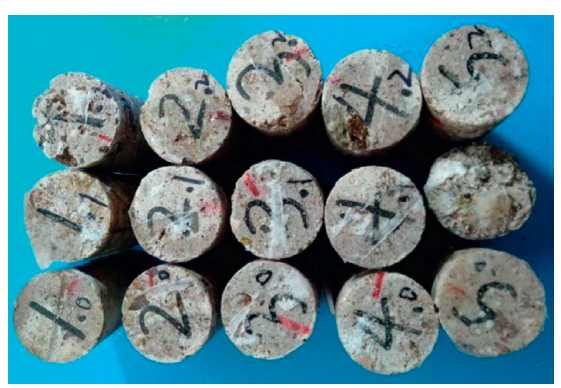

(b)

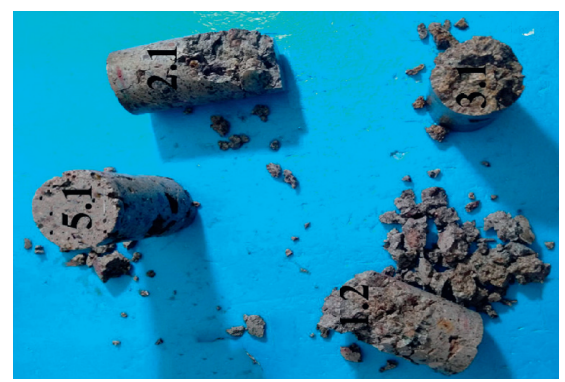

(d)

FIGURE 3: Sample preparation. (a) The samples that have not undergone a freeze-thaw cycle after being saturated with water under a vacuum; (b) the samples in the freezing stage during the 150th freeze-thaw cycle; (c) and (d) the samples after 150 freeze-thaw cycles.

$22^{\circ} \mathrm{C}$. Before and after each freeze-thaw cycle, uniaxial compression experiments were conducted on the representative samples, and the corresponding strength values and physical and mechanical parameters necessary for numerical simulation were obtained. After 150 freeze-thaw cycles, the apparent morphologies of the samples are shown in Figure 5. The results of the uniaxial compression experiment of the samples are shown in Figure 6 and Table 1.

It can be seen from Figure 5 that the color of the representative samples gradually deepened, changing from an initial brown-red-white to a brown-black peat color little by little under the freeze-thaw. In addition, the pits and fine pores on the specimen surface gradually increased and deepened, and the deterioration degree of the specimen was aggravated gradually. The lower end of the specimen went from no crack to full of fine cracks, and the cracks became longer and deeper. The exfoliation of the specimen gradually increased, and finally the lower portion of the specimen broke first. The result is consistent with the experimental conclusion drawn by Yang [48]. As the degree of fragmentation of the specimen increased, the compressive strength of the sample decreased little by little.

In the uniaxial compression experiment, a displacement rate control method with a speed $0.002 \mathrm{~m} / \mathrm{s}$ was adopted. The test results are shown in Table 1. According to Table 1, it can be concluded that the strength of the sample was gradually decreased after each freeze-thaw cycle, and as the number of freeze-thaw cycles increased, the rate of decrease gradually increased until the sample had no bearing capacity. The decrease in rock strength under the action of the freeze-thaw cycles was due to strong freeze-thaw weathering. When the temperature dropped below $0^{\circ} \mathrm{C}$, the water in the rock pores or fissures froze into ice, and the volume expanded (increased by approximately $9 \%$ ), exerting a great pressure on the rock fissures, up to $2000 \mathrm{~kg} / \mathrm{cm}^{2}$. This resulted in a deepening and widening of the fissures in the rock. When the ice melted, water penetrated deeper into the rock along the enlarged fissures. At the same time, the amount of water may also have increased and frozen into the ice again. In this way, the frequent freezing and melting led to the continuous expansion of cracks, which led to the expansion and crushing of rocks along the cracks, and even rock cracks into cuttings under the action of gravity. After calculation, the maximum force, compressive strength, and compressive modulus of the sample were reduced by $98.3 \%, 97.7 \%$, and $97.5 \%$, respectively. Since the sample was taken from the slope, it can represent the slope to a certain extent. Therefore, it can be predicted that the slope will be in a state of limit equilibrium after 150 freeze-thaw cycles. Regarding this issue, the relevant arguments will be provided in the Discussion section.

3.2. Temperature in the Slope. The temperature change trend in the monitored slope is shown in Figure 7. The monitoring data show that before the slope was excavated, it was a permafrost slope, covered with snow, and the slope did not melt all year round. When the slope was cut, part of the slope surface was exposed to the atmosphere. Because permafrost is extremely sensitive to temperature, this caused the slope to gradually melt, causing the temperature in the slope to gradually rise, especially on the sunny slope. In just one year, the slope has melted significantly. The geological survey report showed that the seasonal freeze-thaw depth in this area was $7 \mathrm{~m}$. Due to a large number of continuous ice veins $7 \mathrm{~m}$ below the ground, the ground temperature was basically 

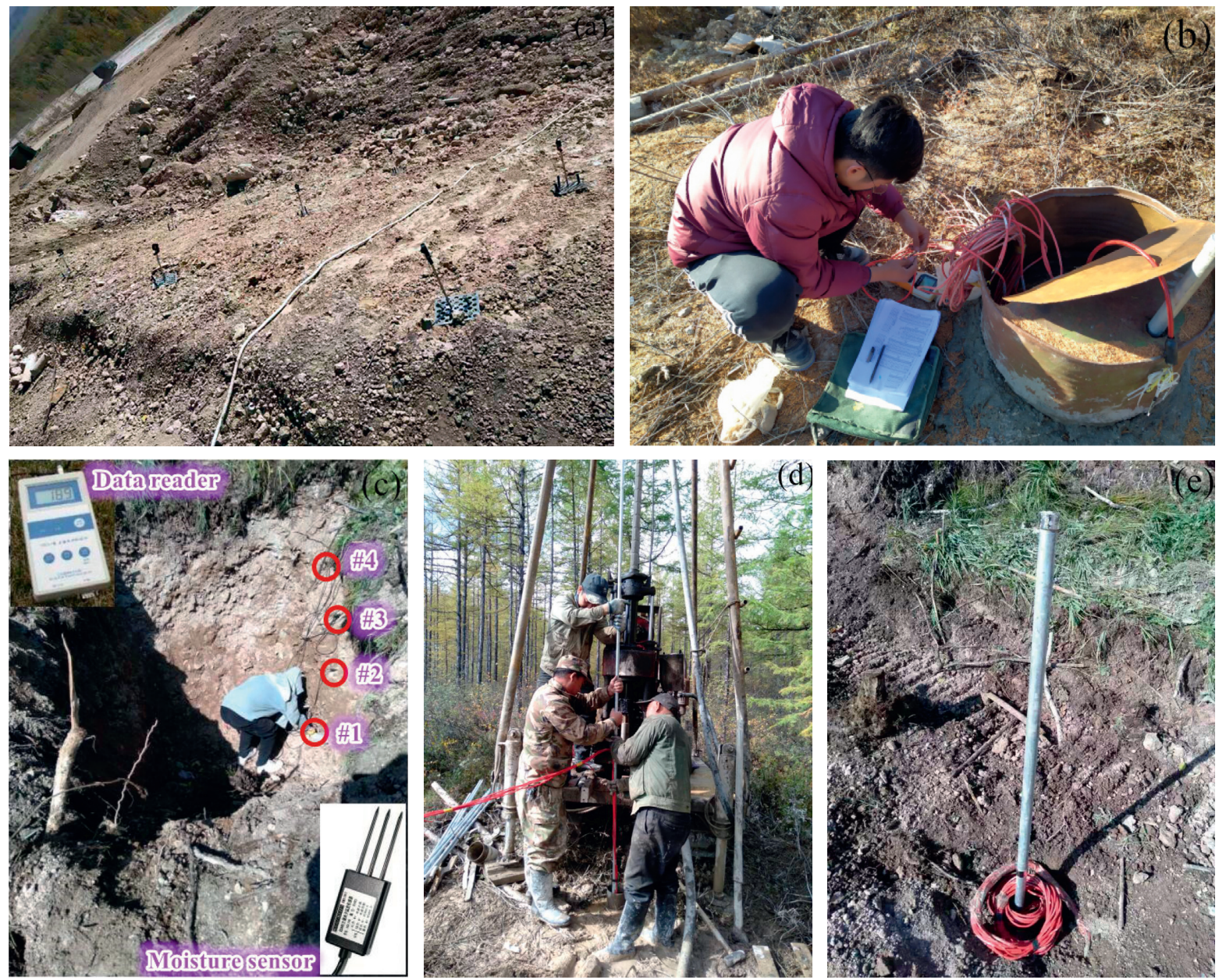

FIgURE 4: Monitoring site layout. (a) The arrangement of observation points on the slope; (b) the measurement process of the temperature data; (c) the arrangement of the moisture sensors; (d) the construction process of temperature sensors; and (e) the datum point when measuring the data.

maintained at $0^{\circ} \mathrm{C}$, so the temperature of $7 \mathrm{~m}$ underground is no longer shown in this paper.

The temperature in this permafrost region had basically been below $-20^{\circ} \mathrm{C}$ since late September. At this time, the underground seasonal active layer had been frozen, but at a depth of $2 \mathrm{~m}$ and below. Hence, its temperature was higher than the temperature in the atmosphere. Therefore, it can be seen from Figure 7 that, during the period from September 22, 2019 to November 1, 2019, the temperature was basically maintained at $0^{\circ} \mathrm{C}$ between $2 \mathrm{~m}$ and $7 \mathrm{~m}$. However, the temperature had a turning point on October 8, 2019. This was because a heavy snow occurred in the permafrost area on October 5, 2019, and the thickness of the snowfall reached $5 \mathrm{~cm}$. Under the protection of the snow cover, the temperature between the depths of $2-7 \mathrm{~m}$ had a short rise during the period from October 4, 2019, to October 8, 2019. After the blizzard, the weather gradually returned to normal, and the temperature gradually decreased and stabilized. In contrast, during the period between September 22, 2019 and November 1,2019, the temperature at a depth of $1 \mathrm{~m}$ in the slope was higher than that at other depths. This was because the position at a depth of $1 \mathrm{~m}$ is relatively shallow, so the \#1 temperature sensor was more affected by the outside ambient temperature. In addition, the slope was a sunny slope with long sunshine time and strong sunshine intensity. The melting of ice and snow on the surface of the slope caused the shallow temperature to rise. At the same time, due to the influence of heavy snow and other freezing weathers, the temperature at a depth of $1 \mathrm{~m}$ dropped between October 4, 2019 and October 8, 2019, and then the temperature rose slightly due to the effect of the snow cover. As the winter arrived, the temperature became lower and lower.

In this permafrost region, winter lasts for seven months, and January has the lowest temperature. Therefore, it can be seen from Figure 7 that, during the period from November 2019 to January 2020 , due to the sudden cold weather, the temperature in the slope showed a linear downward trend. With the passage of time, the cooling rate gradually increased. It can be seen from Figure 7 that the temperature in July was the highest, but it did not exceed $20^{\circ} \mathrm{C}$. During the period from January 2019 to July 2020, due to the rising temperature and the gradual increase in the solar radiation intensity, the temperature in the slope showed a trend of rising in a broken line and reached the highest temperature in July. However, the increase 


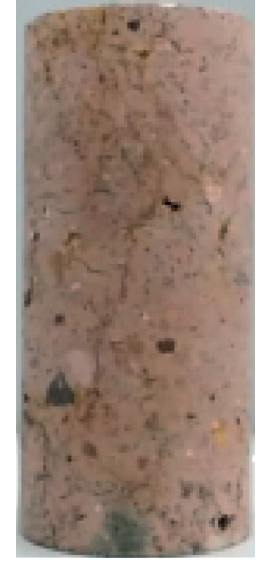

(a)

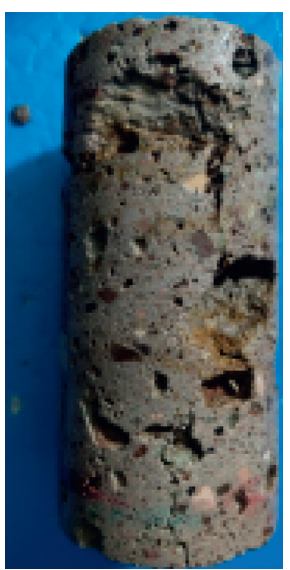

(f)

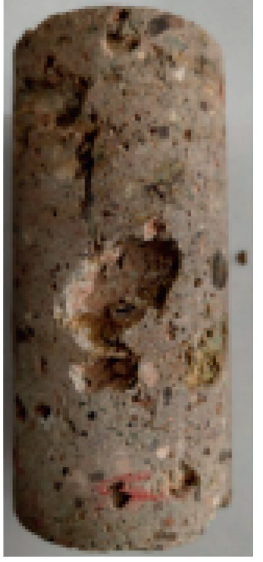

(b)

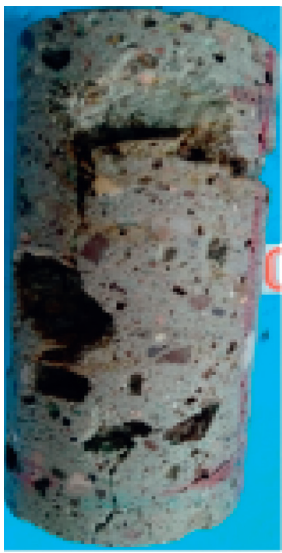

(g)

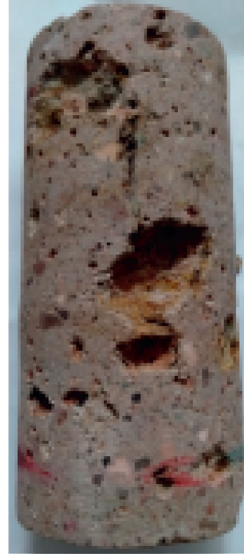

(c)

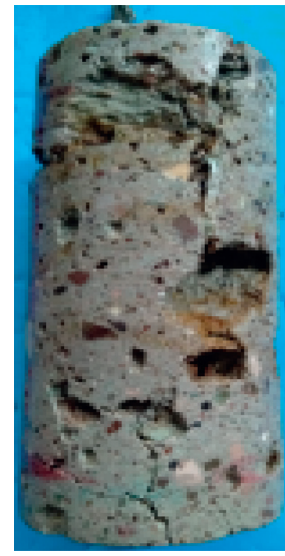

(h)

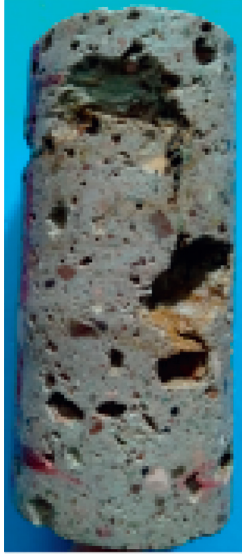

(d)

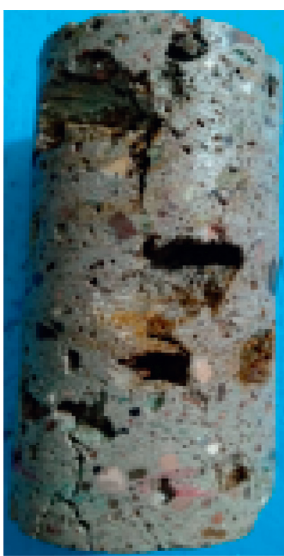

(i)

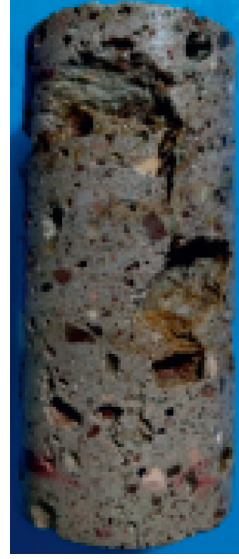

(e)

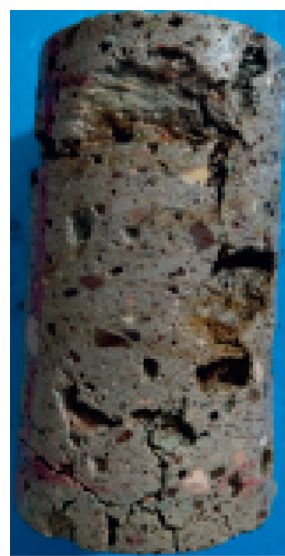

(j)

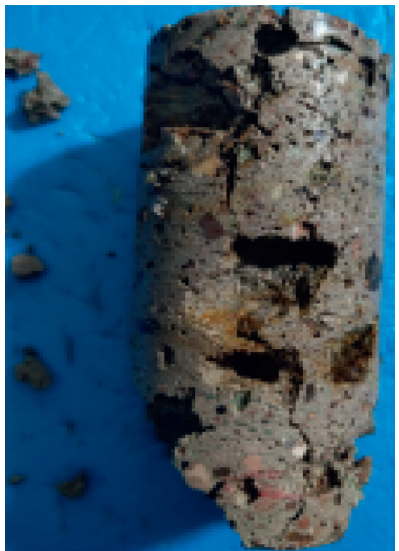

(k)

Figure 5: Apparent morphological changes of the representative samples under the freeze-thaw cycles. (a) $N=0$. (b) $N=40$. (c) $N=50$. (d) $N=60$. (e) $N=70$. (f) $N=80$. (g) $N=90$. (h) $N=100$. (i) $N=110$. (j) $N=130$. (k). $N=150$.

in temperature was smaller than the decrease in temperature during the winter. In autumn, the temperature dropped sharply. When the temperature dropped below $0^{\circ} \mathrm{C}$, a new cycle of freezing and thawing began.

3.3. Moisture in the Slope. The temperature change trend in the monitored slope is shown in Figure 8. It can be seen from
Figure 8 that the water content in the slope changed periodically with the freeze-thaw cycle. The moisture content in the slope is closely related to factors such as atmospheric temperature, rain, snow, wind, and sunshine. During the process of data measurement, in order to reduce the disturbance to the slope and obtain the water content value at each depth of the slope, a pit was not dug on the slope surface, but an experimental pit was dug at a depth of $4 \mathrm{~m}$ at 


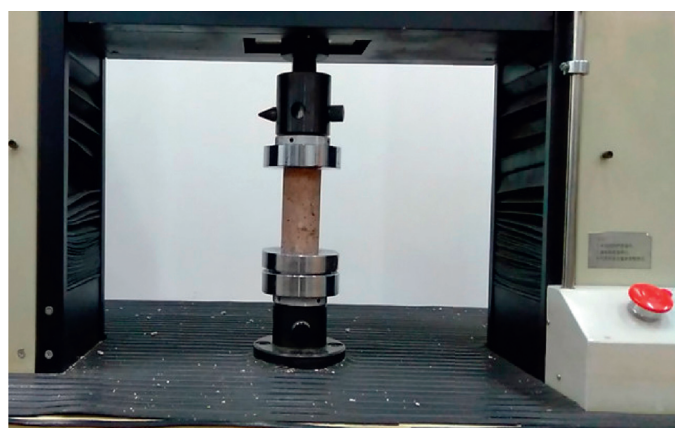

(a)

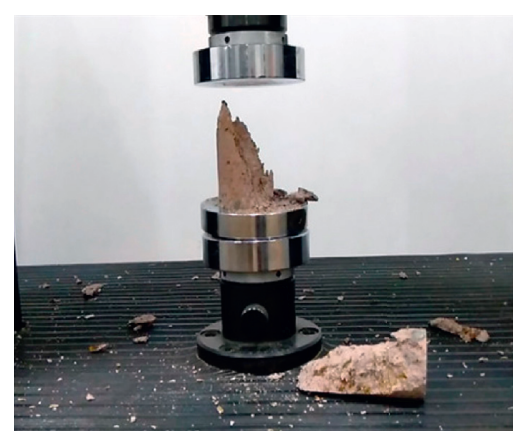

(b)

Figure 6: Uniaxial compression strength test. (a) The representative sample before the uniaxial compression test and (b) the representative sample after the uniaxial compression test.

TABLE 1: Strength values of the representative sample after the different freeze-thaw cycles.

\begin{tabular}{lccc}
\hline Number of freeze-thaw cycles $(N)$ & Compression modulus $E(\mathrm{GPa})$ & Maximum force $(\mathrm{kN})$ & Compression strength $(\mathrm{GPa})$ \\
\hline$N=0$ & 6.54 & 108.69 & 78.93 \\
$N=40$ & 4.89 & 89.43 & 60.91 \\
$N=50$ & 3.73 & 72.85 & 55.68 \\
$N=60$ & 3.28 & 70.14 & 50.35 \\
$N=70$ & 3.09 & 59.86 & 43.46 \\
$N=80$ & 2.71 & 46.80 & 31.22 \\
$N=90$ & 1.87 & 30.76 & 25.69 \\
$N=110$ & 0.59 & 14.21 & 14.98 \\
$N=130$ & 0.34 & 11.53 & 6.84 \\
\end{tabular}

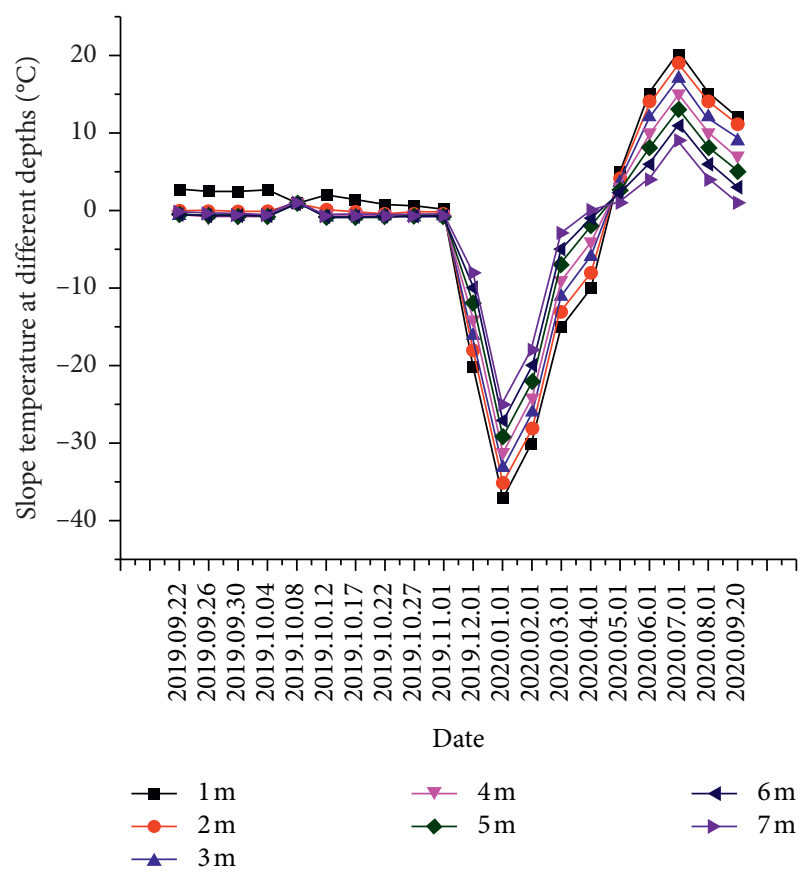

Figure 7: The slope temperature at different depths.

a horizontal distance $3 \mathrm{~m}$ from the slope top. Water sensors were installed vertically on the pit wall at intervals of $1 \mathrm{~m}$, and the layout of the moisture sensor is shown in Figure 4(c).
Since the slope is a high and steep slope, and the surface of the slope has shallow slippage, the process of climbing and digging the pit was very difficult and lasted three days in total. The test pit could only be filled after the moisture sensor had been installed and successfully debugged. The weather during these three days was fine. The temperature was high at noon, the wind was strong, and the sunshine was strong. Therefore, the water loss in the test pit was large. As a result, the water content obtained from September 22, 2019 to September 30, 2019 continued to decrease, and it gradually decreased from the bottom to the top of the slope. On October 2, 2019, the permafrost region ushered in heavy rain, and the rain gradually penetrated into the pit. Because it is a high ice slope with a mixture of soil and rock, water does not easily run off along the slope. This caused the water content of the slope to rise during the period from September 30, 2019 to October 4, 2019, and the closer to the bottom of the pit it is, the greater the water content is.

Because the moisture sensor measures the unfrozen places in the slope, during the period from October 4 th to 8th, 2019, there was a blizzard in the permafrost area that lasted for two days, and the temperature in the area plummeted below $0^{\circ} \mathrm{C}$. This caused the moisture in the slope to freeze into ice. Therefore, the moisture content in the slope dropped sharply, which is shown as a $50^{\circ}$ linear decline in Figure 8. After that, heavy rain and strong solar radiation caused the ice and snow on the surface of the high slope to 


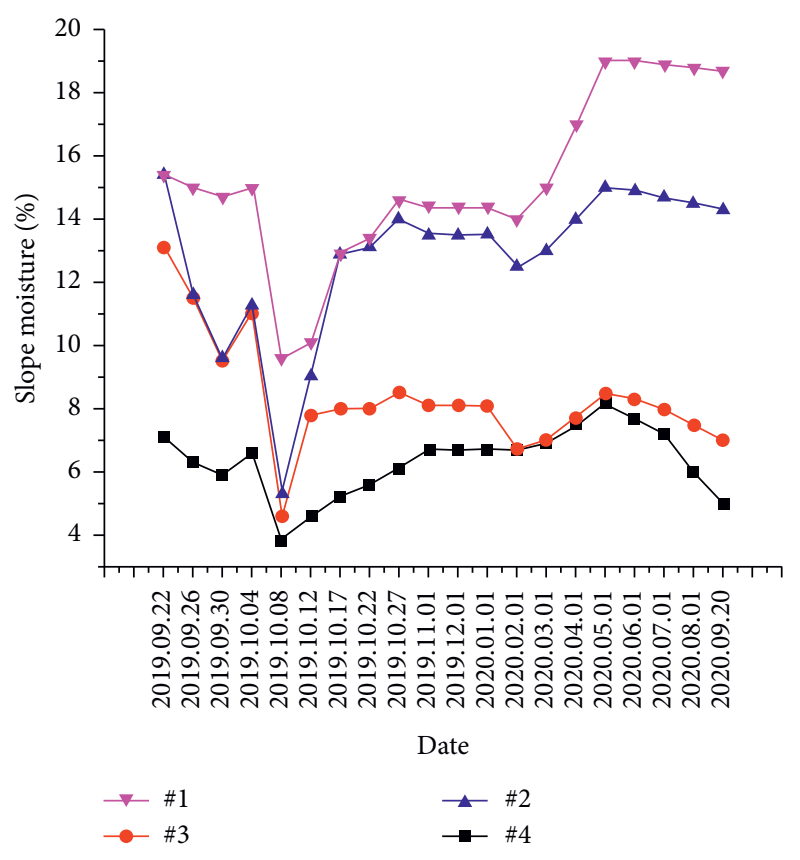

Figure 8: The slope moisture at different depths.

quickly melt, and the water content in the slope began to slowly rise. Since the bottom of the slope was less affected by external disturbances, the water content at the bottom of the slope had always been the largest, and this rising process continued until November 1, 2019. In November, the temperature in this permafrost zone can reach $-20^{\circ} \mathrm{C}$ or even lower, so there is very little replenishment of melted ice and snow. The growth and balance of the various ecological communities in the slope require the consumption of water. In addition, the permafrost region is extremely dry in winter and windy during winter, so the water content in the slope gradually decreases. This process will continue until March 2020. After March 2020, the temperature starts to warm up, and the snow and ice in the slope will begin to melt slowly. With the supplement of rainfall, the water content in the slope gradually increases. In summer, especially in July, the temperature is the highest, so the amount of water loss is large. In addition, most of the ice and snow at this time will have melted, and the replenishment of rain and snow has begun to be less than the evaporation capacity, so that the water content has begun to decrease, which is shown as a downward trend in Figure 8.

It is precisely because of the action of water that after each freeze-thaw cycle, the amount of shallow landslides on the slopes in the permafrost region increases little by little. Repeatedly, it is bound to reduce the stability of the slopes. Therefore, in order to improve the stability of cutting slopes in permafrost regions, the following principles must be adhered to in the design of slope protection and drainage. (1) During the design and construction of the slope, drainage facilities such as intercepting ditches, drainage ditches, side ditches, and seepage ditches should be set up in advance according to the gradient, height, soil quality, catchment area, and other natural parameters, and these facilities

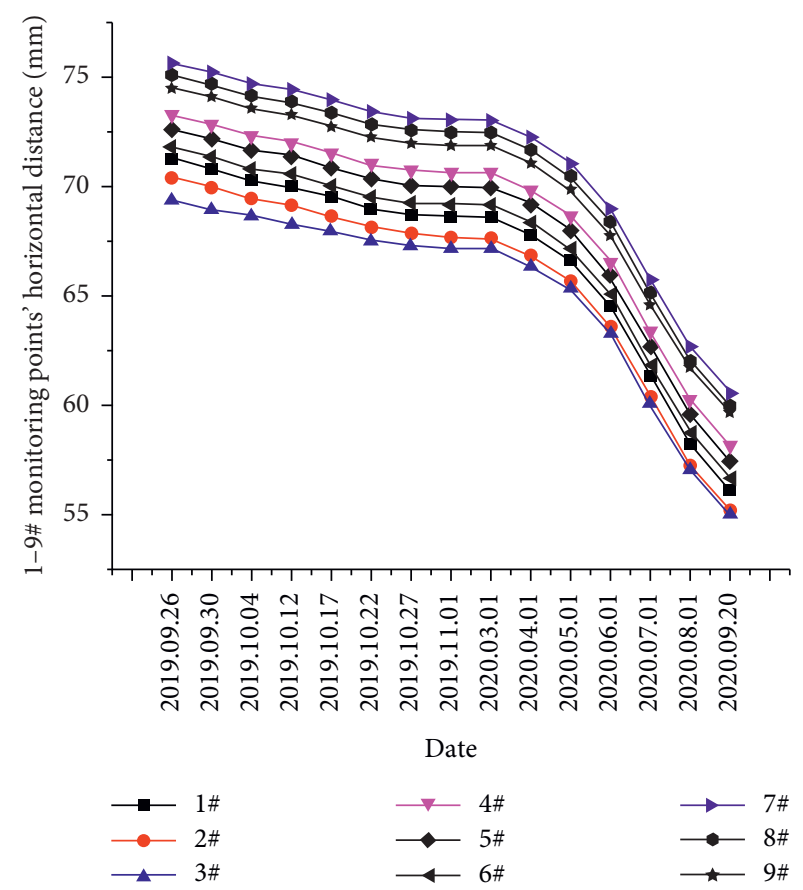

Figure 9: Trend chart of horizontal distance.

should meet the requirements of frost resistance. At the same time, necessary protection and support projects should be set up in areas with loose and broken rock and soil. (2) Drainage works on high and steep slopes or slopes with poor geotechnical stability should be treated with hierarchical interception combined with vertical and horizontal drainage. The surface water beyond the top of the slope must be drained from the intercepting ditch. Each step of the graded slope should be provided with an intercepting ditch for drainage, and a side ditch should also be provided at the toe of the slope. For high and steep slopes, a vertical drainage ditch should be set at a certain distance according to the topography and the size of the slope so that water can be discharged from the slope as soon as possible. (3) In the design of cutting slopes in permafrost regions, consideration must be given to intercepting and excluding the surface water that affects the stability of the slopes to prevent water overflow, stagnation, or infiltration. At the same time, the groundwater that affects the stability of the slope should be cut off, drained, lowered, and directed outside the slope. Only by effectively draining the surface water and groundwater out of the slope and implementing comprehensive treatment can the stability of the slope be ensured. (4) For slopes in permafrost regions, some slope protection projects, such as arched slope protection, retaining walls, and vegetation protection, need to be built to ensure the stability of the slope. In addition, when necessary, supporting structures must be installed at the foot of the slope to improve the ability of resisting freezing and thawing disasters.

3.4. Horizontal Distance of the Slope. When two points are projected onto a horizontal surface, the length between the 


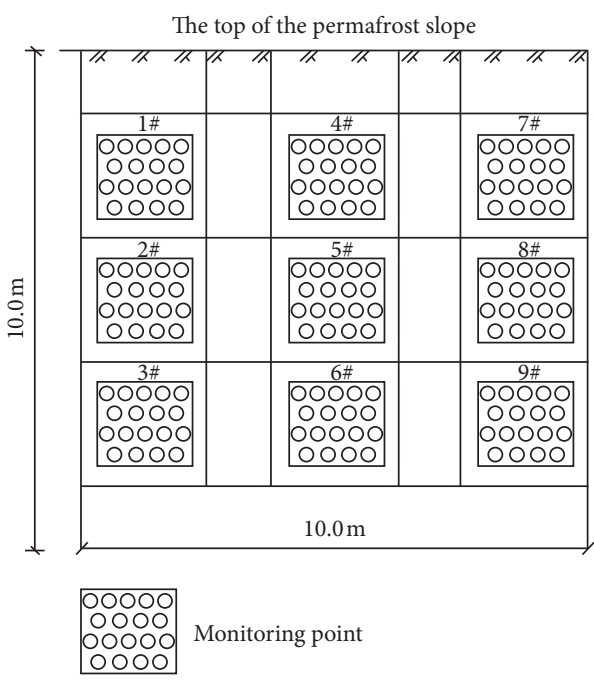

(a)

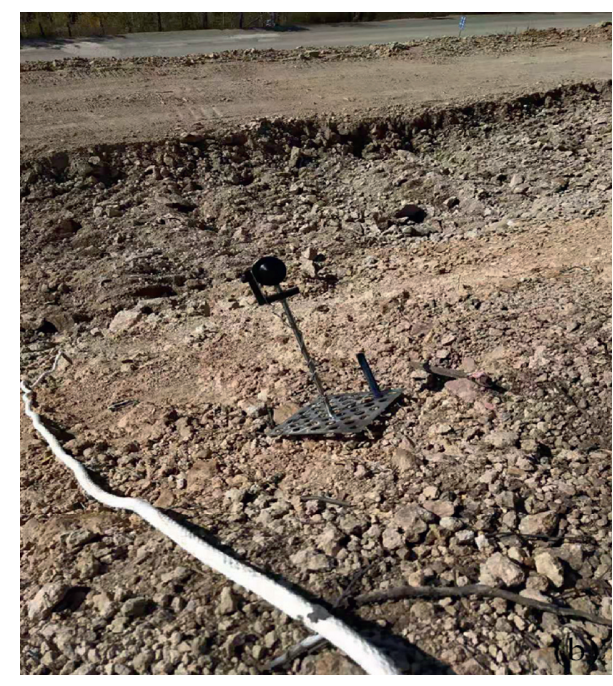

(b)

Figure 10: Schematic diagrams of the monitoring points on the slope. (a) The position of each monitoring point on the slope; and (b) the real view of the monitoring point.

two points is the horizontal distance. In this study, the horizontal distance refers to the length between the monitoring point on the slope and the control point at the foot of the slope after being projected onto the horizontal surface. Since the horizontal distance is directly measured, not calculated, it is easy to obtain. Therefore, the horizontal distance is often used to measure the amount of shallow slippage of a slope under freeze-thaw erosion. The field monitoring data showed that the monitoring points set on the slope changed dynamically with the freeze-thaw cycle. The horizontal distance change trend of each monitoring point is shown in Figure 9.

In order to grasp the shallow slip trend of the slope under the effect of freeze-thaw erosion, one monitoring point was placed every three meters on the slope, and a total of nine monitoring points were arranged. The layout of the monitoring points on the slope is shown in Figure 4(a), and the schematic diagrams of the monitoring points on the slope are shown in Figure 10.

It can be seen from Figure 9 that, during the period from November 1, 2019 to March 1, 2020, the horizontal distance remained basically unchanged, indicating that the location of each monitoring point had not changed. No shallow slip occurred on the slope during the time. The reason is that this period is winter, and the average temperature in this permafrost region can reach $-20^{\circ} \mathrm{C}$ or lower. At this time, the free water in the slope had been frozen into ice, and there was no external water supply. Therefore, the slope did not slip and the positions of the monitoring points on the slope remain unchanged. Therefore, the horizontal distance was shown as a straight line during this period of time. From September 2019 to October 2019 and from April 2020 to July 2020 , the horizontal distances of these two time periods are gradually decreased, but the decrease of the former was not as great as the latter. The reason is that the temperature during the previous period was much lower than the latter.
From April 2020 to July 2020, as time progressed, the value of the horizontal distance began to decrease significantly, and the warmer the weather, the greater the rate of horizontal distance reduction. This was because when the temperature rose to $0^{\circ} \mathrm{C}$ and above, the slope began to melt. Under the action of gravity, the monitoring point on the slope began to slide down along the slope, resulting in the distance between the monitoring point and the control point becoming closer. From July to September, the weather began to slowly cool down, the temperature began to drop, and the slippage of the slope gradually decreased and stabilized and then entered the next freezing period. Under the action of the freeze-thaw cycles, according to the horizontal distance, the height difference between the monitoring point and the control point and at a slope angle of $44^{\circ}$, and the average value of the shallow slip of the slope was calculated to be $6.8 \mathrm{~cm}$.

During the melting season, the annual thermal melt deposition causes the trailing edge slope to melt, crack, and lose support. Then, the unstable active layer, which is in a fluid-plastic state, creeps down slowly along the sliding surface under the action of gravity, as shown in Figure 9. Repeated freeze-thaw cycles cause the shallow rock and soil of the slope to gradually creep down the slope, resulting in the gradual and cumulative failure of the slope. The creep trace is shown in Figure 9. Therefore, the unstable slope in the permafrost region is not formed by a one-time overall sliding. Many engineering practices have proven that, by setting up suitable slope protection facilities and adopting effective slope protection methods, the shallow slippage of slopes in permafrost regions can be effectively controlled.

\section{Discussion}

In order to quantify the degree of degradation of the physical and mechanical properties of the rock and soil in the slope, 


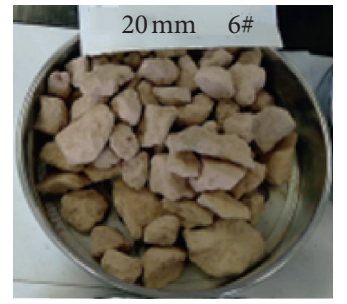

(a)

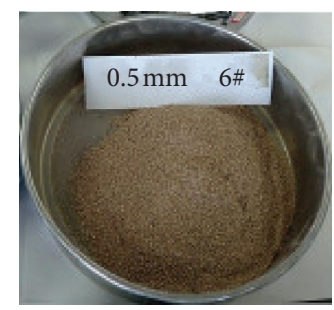

(f)

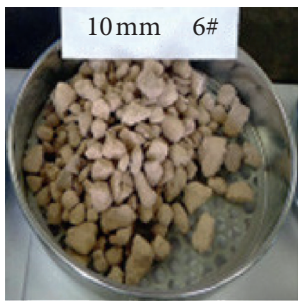

(b)

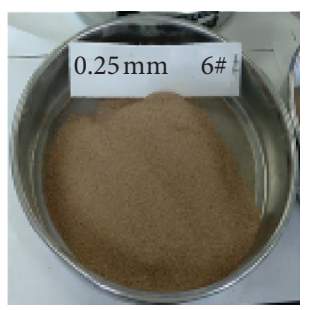

(g)

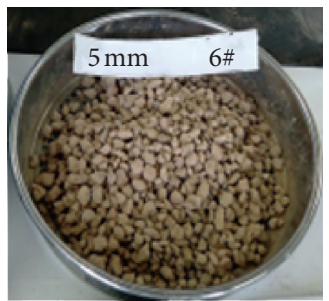

(c)

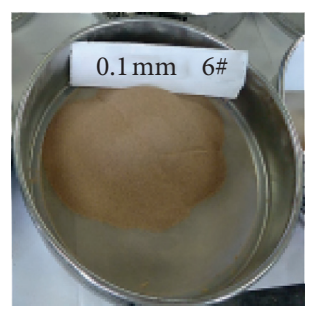

(h)

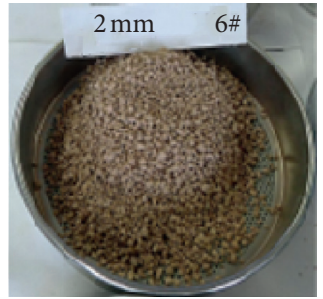

(d)

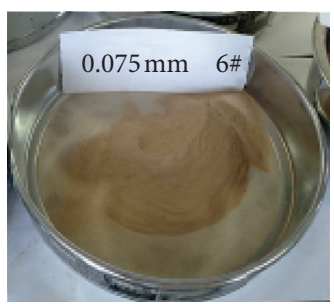

(i)

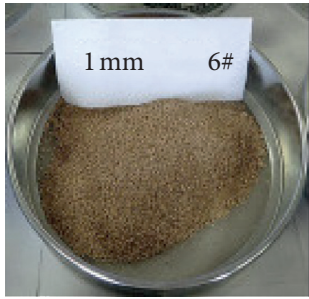

(e)

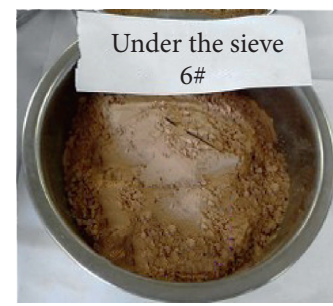

(j)

FIGURE 11: Appearance of the samples on each sieve after the sieving test.

TABLE 2: Required parameters in the ABAQUS numerical model.

\begin{tabular}{lcc}
\hline Density $\left(\mathrm{kg} / \mathrm{m}^{3}\right)$ & Water content $(\%)$ & Cohesion $(\mathrm{kPa})$ \\
\hline 1968 & 6.93 & 2.88 \\
Internal friction angle $\left(^{\circ}\right)$ & Linear expansion coefficient $\left(10^{-6}\right)$ & Thermal conductivity $(\mathrm{W} / \mathrm{m} \times \mathrm{K})$ \\
27.35 & 9.73 & 0.47 \\
Specific heat capacity $\left(\mathrm{J} /\left(\mathrm{g} .{ }^{\circ} \mathrm{C}\right)\right)$ & Elastic modulus $(\mathrm{GPa})$ & Compressive strength $(\mathrm{GPa})$ \\
0.86 & 6.54 & 78.93 \\
\hline
\end{tabular}

the freeze-thaw erosion was studied. Core-drilling sampling was conducted in the slope. A total of 150 freeze-thaw cycle experiments and uniaxial compressive strength experiments were conducted on the samples. The experimental results showed that after 150 freeze-thaw cycles, the maximum force, compressive strength, and compressive modulus of the samples were reduced by $98.3 \%, 97.7 \%$, and $97.5 \%$, respectively. In addition, the samples had no bearing capacity. Therefore, the conclusion was that the slope was already at the limit equilibrium state at this time. With the aid of the ABAQUS numerical model, this conclusion was demonstrated as follows.

In order to truly reflect the shallow slippage of the slope in nature during a freeze-thaw cycle, we set the number of freeze-thaw cycles of the slope in the ABAQUS numerical model as 150 . On the basis of previous studies and the statistical monthly average temperature of the area where the slope is located from 2017 to 2019, as well as the existing experimental conditions and equipment, we define the freezing temperature of the slope as $-20^{\circ} \mathrm{C}$ and the melting temperature of the slope as $22^{\circ} \mathrm{C}$; the freezing process lasts for 12 hours, and the melting process lasts for 12 hours. The constitutive model adopts the Mohr Coulomb Plasticity model. The slope instability is evaluated based on the displacement inflection point of the slope shoulder. In addition, various experiments were conducted to determine the parameters required for the numerical simulation. The purpose of the screening experiment was to obtain the ratio of soil to rock in the soil-rock mixture slope and the threshold between soil and rock. The results of the screening experiments showed that the volume ratio of soil to rock in the slope was $69.38 \%: 30.62 \%$ and the threshold between the soil and rock in the slope was set to $5 \mathrm{~mm}$, as shown in Figure 11. The physical parameters, mechanical parameters, and thermal parameters required in the ABAQUS numerical model are shown in Table 2. According to the actual size of the slope, the above data were written into code in Python software and then run in ABAQUS software, and finally the slope model was obtained, as shown in Figure 12(a). The constraints set in the ABAQUS model were that the horizontal displacement was restricted on the left and right sides of the slope, the bottom was hinged, and the other boundaries were free and unconstrained. The film coefficient in this model was chosen to be $20 \mathrm{~W} / \mathrm{m}^{2} \times{ }^{\circ} \mathrm{C}$. After 150 freeze-thaw cycles, the shallow slip of the slope was obtained, as shown in Figure 12(b).

In Figure 12(b), when the soil-rock slope was on the verge of instability after 150 freeze-thaw cycles, the maximum slip calculated by the ABAQUS numerical simulation model is $6.811 \mathrm{~cm}$, and its safety factor was less than 1 , as shown in Figure 13. The place with the greatest amount of slip was the shoulder of the slope, which was consistent with the results of the uniaxial compression tests and field measurements, as shown in Table 1 and Figure 14. In Figure 14, the Pythagorean theorem was used to calculate the amount of slip along the slope surface at any point on the 


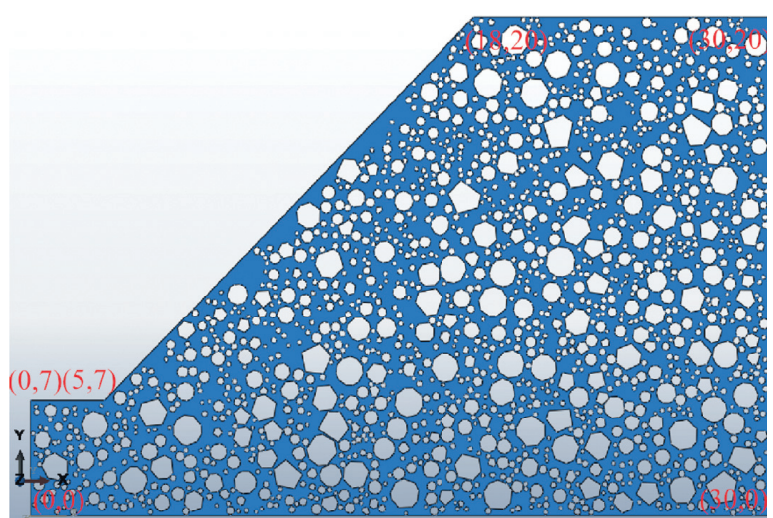

(a)

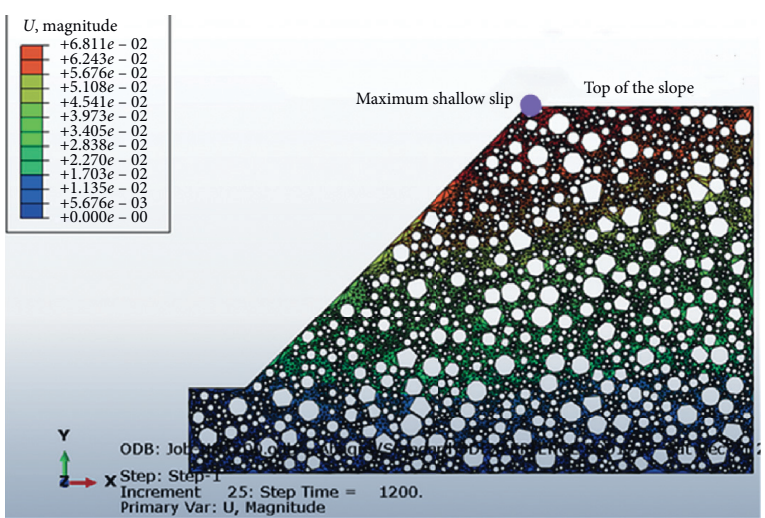

(b)

FIgURE 12: Soil-rock mixture slope in ABAQUS. (a) The slope model in ABAQUS and (b) the shallow slip of the slope after 150 freeze-thaw cycles.

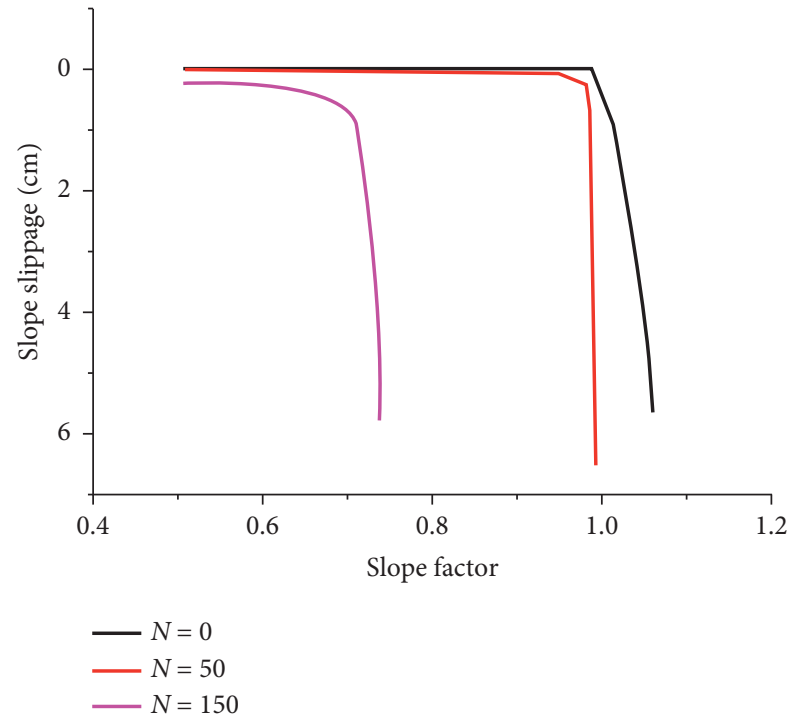

FIGURE 13: Safety factor of the slope.

slope based on the change in the height difference, slope angle, and horizontal distance, as shown in Figure 9. After calculation, the \#7 monitoring point located on the top of the slope had the largest slip, which was $6.805 \mathrm{~cm}$. It can be concluded that the error between the slip calculated in the numerical simulation and the actual monitoring value was less than $1 \%$, which verified the correctness of the model.

There are obvious limitations in this research, which are worthy of improvement in future research. The slope in this permafrost area was a three-level slope. Due to the impact of phased construction, monitoring and experimental research was only conducted on the shallow slippage of the first-level slope under the effect of freezing and thawing. Below the secondary slope is the existing secondary road, and below the tertiary slope is the existing railway. Both the road and the railway are in operation. Therefore, the shallow slip of the second-level and third-level slopes under the freeze-thaw cycles has great research value. In the future, in order to fully grasp the amount of shallow slippage of multilevel slopes

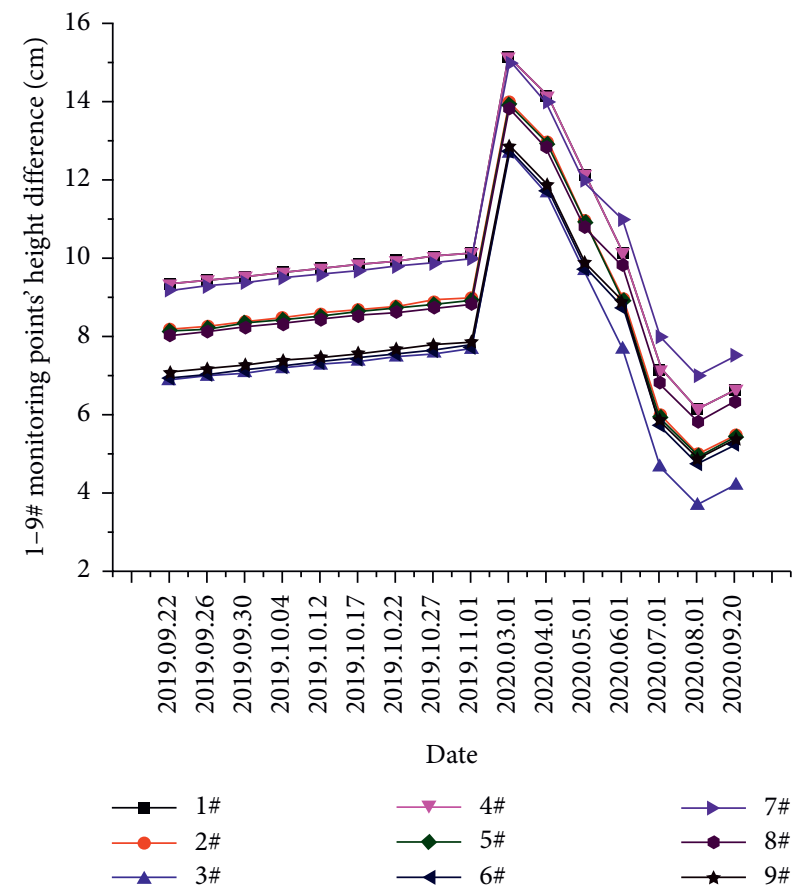

FIgURE 14: The height difference change diagram of the monitoring point on the slope.

under the effects of freeze-thaw and to investigate the degree to which freeze-thaw erosion will reduce the stability of slopes, tests will be conducted on all the primary, secondary, and tertiary slopes. Side field monitoring and indoor experiments will be performed to provide useful experience for the design, construction, operation, and management of cutting slopes in permafrost areas.

\section{Conclusions}

This study conducted an investigation on the stability of soilrock road cutting slopes in high-latitude and low-altitude permafrost regions of the Greater Khingan Mountains in the Inner Mongolia Autonomous Region, which provided a 
reliable basis for accurately assessing the effect of freezethaw cycles on the slope stability. The construction processes of temperature sensors, moisture sensors, control points, and monitoring points on the slope were very complicated in the permafrost region. Environmental factors and the steep slope with a loose surface and high ice content made this research particularly difficult. The following conclusions were obtained from this research:

(1) The field monitoring data showed that the slope changed dynamically with the freeze-thaw cycles. A shallow slip of the slope began during the spring melting season, and the higher the atmospheric temperature, the greater the amount of shallow slip of the slope. In addition, the closer to the top of the slope it is, the greater the amount of shallow slip is. In winter, since the slope in this permafrost region was frozen, only frost heaves occurred, and there was no slippage. In addition, slope slippage was also affected by factors such as rain, snow, wind, sunshine, construction, slope protection measures, and drainage facilities.

(2) In order to quantify the degree of degradation of the slope caused by freeze-thaw erosion, indoor freezethaw cycle experiments and uniaxial compression experiments were conducted on the samples in the slope. The experimental results showed that repeated freeze-thaw erosion caused irreversible damage to the samples. After 150 freeze-thaw cycles, the samples were fragmented with little bearing capacity. In addition, based on the horizontal distance and height difference data of the monitoring points on the slope, it was concluded that the slope was in a state of extreme equilibrium and was on the verge of a landslide. This result was consistent with the conclusion of the numerical simulation calculation that obtained a safety factor of less than 1 . Therefore, the freeze-thaw cycle is the first influencing factor that leads to permafrost slope instability.

(3) In a freezing and thawing environment, water is the dominant factor that causes the shallow slippage of a slope in permafrost regions. Therefore, in order to reduce the amount of shallow slippage, effective slope top water blocking facilities, slope drainage facilities, and slope bottom drainage facilities must be constructed. In addition, the best slope protection measures must be adopted according to the actual situation of the slope location and local conditions. Additionally, a landslide warning mechanism should be constructed on the slope to the extent possible. In short, when constructing a cutting slope in a permafrost area, the emphasis should be on measures for protecting the frozen soil from the design stage until the end of the slope operation period.

\section{Data Availability}

The figures presenting the test data analysis were all drawn in AutoCAD 2019 and Origin 8.0. The raw data are presented in the figures, including the temperature data diagram, moisture data diagram, horizontal angle change charts of landmarks, vertical angle change charts of landmarks, height difference change charts of landmarks, and horizontal distance change charts of landmarks.

\section{Additional Points}

Patents. The Chinese invention patent is as follows:

(1) Invention patent name: supporting device for high water-containing slope and construction method thereof

Application publication number: CN109056756A

Applicant: China University of Geosciences (Beijing)

Inventor: Yuxia Zhao

Invention patent abstract: the invention discloses a supporting device for a high water-containing slope, which comprises a plurality of transverse and longitudinal steel bars arranged in a network, and an anchor post is provided at the overlap of the transverse and longitudinal steel bars. An anchor head is fixed at the bottom of the anchor post, and a blind hole is provided in the inner hole. An inner sleeve is movably inserted in the blind hole. The inner sleeve is provided with two through holes that are perpendicular to each other. A mating block is provided in the inner sleeve. The top of the inner sleeve is connected to the first adjusting rod through a first bearing. The first adjusting rod and the inner sleeve are provided with through-thread holes. The second adjusting rod, the bottom of the second adjusting rod, is axially connected to the pressing block through the second bearing, the pressing block is crimped to the transverse reinforcing bar, and a protective net is connected between the transverse reinforcing bar and the longitudinal reinforcing bar. The invention can improve the shortcomings of the prior art, improve the protection effect on the slope, reduce soil erosion of the slope, and protect the ecological environment.

\section{Conflicts of Interest}

The authors declare that there are no conflicts of interest regarding the publication of this paper.

\section{Authors' Contributions}

Conceptualization was made by Hongyan Liu, Yuxia Zhao, Jun Feng, Kangqi Liu, and Hongwei Xu; methodology was achieved by Yuxia Zhao and Jun Feng; software was done by Hongyan Liu, Yuxia Zhao, and Kangqi Liu; validation was got by Jun Feng, Hongwei $\mathrm{Xu}$, and Liqun Wang; investigation was provided by Yuxia Zhao, Jun Feng, and Kangqi Liu; resources were provided by Jun Feng and Liqun Wang; data was created by Yuxia Zhao, Jun Feng, and Kangqi Liu; original draft preparation was written by Yuxia Zhao and Jun Feng; review and editing were written by Yuxia Zhao 
and Kangqi Liu; project administration was achieved by Hongyan Liu, Jun Feng, Liqun Wang, and Hongwei Xu; project financial acquisition was got by Hongyan Liu, Jun Feng, and Liqun Wang, Yuxia Zhao, and Kangqi Liu. All authors have read and agreed to the published version of the manuscript.

\section{Acknowledgments}

The authors gratefully acknowledge the School of Engineering and Technology, China University of Geosciences (Beijing), and Beijing Municipal Road \& Bridge (Group) Co., Ltd., for the financial support, surveyed data, and comments of the project (Key Techniques of Frozen Soil Road Construction in High-Latitude and Low-Altitude Forest Area). The authors would also like to thank Guangxi Road and Bridge Engineering Group Co., Ltd., and others in this collaborative project that have helped them in drilling, sampling, equipment, transportation, and accommodation. In addition, they thank LetPub (http://www.letpub.com) for its linguistic assistance during the preparation of this manuscript. These supports are greatly appreciated.

\section{References}

[1] W. Ma and D. Y. Wang, Frozen Soil Mechanics, Science Press, Beijing, China, 2019.

[2] R. Y. Yang and Y. Li, Frozen Soil Engineering, China Construction Industry Press, Beijing, China, 2020.

[3] Y. W. Zhou, D. X. Guo, G. Q. Qiu, G. D. Cheng, and S. D. Li, Geocryology in China, Science Press, Beijing, China, 2000.

[4] X. Hou, Frozen Soil Destruction Mechanics, Science Press, Beijing, China, 2018.

[5] Y. Song, L. Jin, H. Peng, and H. Liu, "Development of thermal and deformation stability of Qinghai-Tibet highway under sunny-shady slope effect in southern Tanglha region in recent decade," Soils and Foundations, vol. 60, no. 2, pp. 342-355, 2020.

[6] H. Yan and Y. X. Zhao, "Theoretical calculation of frost heaving pressure in tunnel surrounding rock during freezethaw cycles," Journal of Central South University of Science and Technology, vol. 51, pp. 1049-1508, 2020.

[7] D. Rui, M. Ji, D. Nakamur, and T. Suzuki, "Experimental study on gravitational erosion process of vegetation slope under freeze-thaw," Cold Regions Science and Technology, vol. 151, pp. 168-178, 2018.

[8] B. Chen, S. Zhang, Y. Li, Z. Li, and H. Zhou, "Physical simulation study of crack propagation and instability information discrimination of rock-like materials with faults," Arabian Journal of Geosciences, vol. 13, no. 18, Article ID 966, 2020.

[9] G. Shi, X. Yang, H. Yu, and C. Zhu, "Acoustic emission characteristics of creep fracture evolution in double-fracture fine sandstone under uniaxial compression," Engineering Fracture Mechanics, vol. 210, pp. 13-28, 2019.

[10] F. Q. Ren, C. Zhu, and M. He, "Moment tensor analysis of acoustic emissions for cracking mechanisms during schist strain burst," Rock Mechanics and Rock Engineering, vol. 53, no. 1, pp. 153-170, 2020.

[11] C. Zhu, Z. G. Tao, S. Zhao, and S. Yang, "V shaped gully method for controlling rockfall of high-steep slope in China,"
Bulletin of Engineering Geology and the Environment, vol. 78, pp. 2731-2747, 2019.

[12] Z. Tao, Y. Wang, C. Zhu, H. Xu, G. Li, and M. He, "Mechanical evolution of constant resistance and large deformation anchor cables and their application in landslide monitoring," Bulletin of Engineering Geology and the Environment, vol. 78, no. 7, pp. 4787-4803, 2019.

[13] Y. Shin, J. C. Choi, S. Quinteros, I. Svendsen, J.-S. L'Heureux, and J. Seong, "Evaluation and monitoring of slope stability in cold region: case study of man-made slope at Øysand, Norway," Applied Sciences, vol. 10, no. 12, p. 4136, 2020.

[14] Y. L. Chou, L. Y. Sun, B. A. Li, and X. L. Wang, "Effects of freeze-thaw cycle and dry-wet alternation on slope stability," Cold Regions Science and Technology, vol. 11, pp. 159-172, 2019.

[15] H. Huang, T. Babadagli, X. Chen, H. Li, and Y. Zhang, "Performance comparison of novel chemical agents for mitigating water-blocking problem in tight gas sands," $S P E$ International Conference and Exhibition on Formation Damage Control, vol. 1, pp. 1-9, 2020.

[16] G. Feng, X. Wang, M. Wang, and Y. Kang, "Experimental investigation of thermal cycling effect on fracture characteristics of granite in a geothermal-energy reservoir," Engineering Fracture Mechanics, vol. 235, Article ID 107180, 2020.

[17] G. Feng, Y. Kang, X. Wang, Y. Hu, and X. Li, "Investigation on the failure characteristics and fracture classification of shale under Brazilian test conditions," Rock Mechanics and Rock Engineering, vol. 53, no. 7, pp. 3325-3340, 2020.

[18] C. Zhu, M. C. He, M. Karakus, X. B. Cui, and Z. G. Tao, "Investigating toppling failure mechanism of anti-dip layered slope due to excavation by physical modelling," Rock Mechanics and Rock Engineering, vol. 53, pp. 5029-5050, 2020.

[19] Y. L. Zhang, L. G. Zhou, J. Wang, C. L. Wu, and X. Lv, "Effects of freeze-thaw cycles on mechanical properties of silty sand and subgrade slope stability," Journal of Jilin University (Engineering and Technology Edition), vol. 49, pp. 1531-1538, 2019.

[20] D. Qu, Y. Luo, X. Li, G. Wang, G. Zhang, and K. Xu, "Study on the stability of rock slope under the coupling of stress field, seepage field, temperature field and chemical field," Arabian Journal for Science and Engineering, vol. 45, no. 10, p. 8315, 2020.

[21] H. Y. Pan, D. W. Yin, N. Jiang, and Z. G. Xia, "Crack initiation behaviors of granite specimens containing crossing-doubleflaws with different lengths under uniaxial loading," Advances in Civil Engineering, vol. 2020, Article ID 8871335, 13 pages, 2020.

[22] J. Wang, Y. Zhang, Z. Qin, S. Song, and P. Lin, “Analysis method of water inrush for tunnels with damaged waterresisting rock mass based on finite element method-smooth particle hydrodynamics coupling," Computers and Geotechnics, vol. 126, Article ID 103725, 2020.

[23] J. T. Chen, J. Zhao, S. Zhang, Y. Zhang, F. Yang, and M. Li, "An experimental and analytical research on the evolution of mining cracks in deep floor rock mass," Pure and Applied Geophysics, vol. 177, pp. 3058-3081, 2020.

[24] D. Z. Ren, D. Zhou, D. Liu, F. Dong, S. Ma, and H. Huang, "Formation mechanism of the upper triassic Yanchang formation tight sandstone reservoir in Ordos basin-take Chang 6 reservoir in Jiyuan oil field as an example," Journal of Petroleum Science and Engineering, vol. 178, pp. 497-505, 2019.

[25] X. Wang, C. Liu, S. Chen, L. Chen, K. Li, and N. Liu, "Impact of coal sector's de-capacity policy on coal price," Applied Energy, vol. 265, Article ID 114802, 2020. 
[26] D. Liu, Z. Gu, R. Liang et al., "Impacts of pore-throat system on fractal characterization of tight sandstones," Geofluids, vol. 2020, Article ID 4941501, 17 pages, 2020.

[27] C. X. Wang, B. T. Shen, J. T. Chen et al., "Compression characteristics of filling gangue and simulation of mining with gangue backfilling: an experimental investigation," Geomechanics and Engineering, vol. 20, pp. 485-495, 2020.

[28] J. Xu, X. Zheng, and H. Zhang, "Analysis on mechanism and stability of freeze-thaw spalling disease for slope in loess region," Journal of Xi'an University of Architecture and Technology (Natural Science Edition), vol. 50, pp. 477-484, 2018.

[29] J. Xu, A. Haque, W. Gong et al., "Experimental study on the bearing mechanisms of rock-socketed piles in soft rock based on micro X-ray CT analysis," Rock Mechanics and Rock Engineering, vol. 53, no. 8, pp. 3395-3416, 2020.

[30] T. Wang, P. Li, Y. Liu et al., "Experimental investigation of freeze-thaw meltwater compound erosion and runoff energy consumption on loessal slopes," Catena, vol. 185, Article ID 104310, 2020.

[31] M. Akarli, W. Prince, and R. Siddique, "Damage in granite under heating/cooling cycles and water freeze-thaw condition," International Journal of Rock Mechanics and Mining Sciences, vol. 45, pp. 1164-1175, 2008.

[32] G. Khanlari and Y. Abdilor, "Influence of wet-dry, freezethaw, and heat-cool cycles on the physical and mechanical properties of Upper Red sandstones in central Iran," Bulletin of Engineering Geology and the Environment, vol. 74, no. 4, pp. 1287-1300, 2015.

[33] J. Xu, J. Ren, Z. Wang, S. Wang, and J. Yuan, "Strength behaviors and meso-structural characters of loess after freezethaw," Cold Regions Science and Technology, vol. 148, pp. 104-120, 2018.

[34] D. Chang and J. K. Liu, "Review of the influence of freeze-thaw cycles on the physical and mechanical properties of soil," Sciences in Cold and Arid Regions, vol. 5, pp. 457-460, 2013.

[35] Q. Ma, K. Zhang, J. D. Jabro, L. Ren, and H. Liu, "Freeze-thaw cycles effects on soil physical properties under different degraded conditions in Northeast China," Environmental Earth Sciences, vol. 78, no. 10, p. 321, 2019.

[36] A. Momeni, Y. Abdilor, G. R. Khanlari, M. Heidari, and A. A. Sepahi, "The effect of freeze-thaw cycles on physical and mechanical properties of granitoid hard rocks," Bulletin of Engineering Geology and the Environment, vol. 75, no. 4, pp. 1649-1656, 2016.

[37] L. Y. Wang, Y. Xiao, L. Jiang, and Z. Y. Ouyang, “Assessment and analysis of the freeze-thaw erosion sensitivity on the Tibetan Plateau," Journal of Glaciology and Geocryology, vol. 39, pp. 61-69, 2017.

[38] P. Wang, J. Xu, S. Liu, H. Wang, and S. Liu, "Static and dynamic mechanical properties of sedimentary rock after freeze-thaw or thermal shock weathering," Engineering $\mathrm{Ge}$ ology, vol. 210, pp. 148-157, 2016.

[39] Y. X. Zhou, "The deterioration law of frozen rock during freeze-thaw cycles in the tibetan high altitude," Master thesis, Southwest Jiaotong University, Chengdu, China, 2015.

[40] The National Standards Compilation Group of People's Republic of China, GB/T50266-2013. Engineering Rock Mass Test Method Standards, Planning Press of China, Beijing, China, 2013.

[41] T. C. Chen, M. R. Yeung, and N. Mori, "Effect of water saturation on deterioration of welded tuff due to freeze-thaw action," Cold Regions Science and Technology, vol. 38, no. 2-3, pp. 127-136, 2004.

[42] A. C. William, Freezing and Thawing of Concrete Mechanisms and Control, American Concrete Institute, Farmington Hills, MI, USA, 1967.

[43] L. G. Wang, F. He, X. F. Liu, and Y. J. Yu, "Non-linear creep model and stability analysis of rock," Chinese Journal of Rock Mechanics \& Engineering, vol. 23, pp. 1640-1642, 2004.

[44] G. T. Liu, Y. Hu, F. Q. Chen, and Z. H. Xu, "Rheological property of soft rock under multiaxial compression and its effect on design of arch dam," Chinese Journal of Rock Mechanics and Engineering, vol. 23, pp. 1237-1241, 2004.

[45] J. J. He and J. P. Shi, "Shear failure properties of sandstone with different moisture contents after cyclic freezing-thawing," Chinese Journal of Rock Mechanics and Engineering, vol. 37, pp. 1350-1358, 2018.

[46] T.-K. Tan and W.-F. Kang, "Locked in stresses, creep and dilatancy of rocks, and constitutive equations," Rock Mechanics Felsmechanik Mcanique des Roches, vol. 13, no. 1, pp. 5-22, 1980.

[47] The Professional Standards Compilation Group of People's Republic of China, DZ/T0276.25-2015. Regulation for Testing the Physical and Mechanical Properties of rock, Standards Press of China, Beijing, China, 2015.

[48] G. S. Yang, Y. Wei, Y. J. Shen et al., "Mechanical behavior and strength forecast model of frozen saturated sandstone under triaxial compression," Chinese Journal of Rock Mechanics and Engineering, vol. 38, pp. 683-694, 2019. 